\title{
Should we vaccinate the better seroconverters or the most vulnerable? Game changing insights for COVID-19 vaccine prioritization policies
}

\author{
Antoine AbdelMassih ${ }^{1,2^{*}}$, Meryam El Shershaby ${ }^{3}$, Hanya Gaber $^{3}$, Menna Habib $^{3}$, Nada Gamal ${ }^{3}$, \\ Reem Husseiny ${ }^{3}$, Nada AlShehry ${ }^{3}$, Abeer Amin ${ }^{3}$, Bassant Heikal ${ }^{3}$, Nadine El-Husseiny ${ }^{4,5}$, Mai Moursi ${ }^{3}$, \\ Habiba-Allah Ismail ${ }^{3}$, Sara Senoussy ${ }^{3}$, Reem ElSharkawy ${ }^{3}$, Hebat Allah AlZayat ${ }^{3}$, Ghada ElMahdy ${ }^{3}$, \\ Hossameldin Moawad ${ }^{3}$, Ali Genena ${ }^{3}$, Ahmed ElKiki ${ }^{3}$, Mary Reda ${ }^{3}$, Mohamed Khalil ${ }^{3}$, Reem Al Ramady ${ }^{3}$, \\ Noran Radwan ${ }^{3}$, Mariam Khaled-Ibn-EIWalid ${ }^{3}$, Hager Amin ${ }^{3}$, Rafeef Hozaien ${ }^{3}$, Aya Kamel ${ }^{3}$ and Raghda Fouda ${ }^{6,7}$
}

\begin{abstract}
Background: With the rapid rise in COVID 19 cases incomparable to the number of vaccinations available, there has been a demand to prioritize the older age groups receiving the vaccine as they have more risk of morbidity and mortality and thus better outcome from vaccination.
\end{abstract}

Main body: Some studies showed a lower seroconversion rate in older group patients; thus, we discuss the necessity to reprioritize vaccinations to younger age groups who have better seroconversion rates, but we may face some ethical dilemma that could hinder our hypothesis. Decreased seroconversion rates in adults are attributable to immunosenescence which involves a decrease in humoral and cellular-mediated immunity with age. Despite this fact, there remains some ethical dilemma that can hinder widespread vaccination of younger generations, the most important of which is the unknown long-term effects of COVID-19 vaccines due their fast-tracking under the pressure of the pandemic.

Short conclusion: Prioritizing children vaccination against COVID-19 seems an interesting strategy that can help in containing the pandemic. Resolving some ethical dilemma needs to be done before implementing such strategy.

Keywords: Seroconversion, COVID-19 vaccines, Prioritization policy

\section{Background}

The COVID-19 pandemic started in February of 2020. Since then, the virus has spread worldwide, reaching more than 200 million confirmed cases of COVID-19 and more than 4 million deaths (as reported by the WHO on August 6, 2021). Most infected children experienced

\footnotetext{
*Correspondence: antoine.abdelmassih@kasralainy.edu.eg

2 Pediatric Cardio-Oncology Clinic, Children Cancer Hospital of Egypt,

Cairo, Egypt

Full list of author information is available at the end of the article
}

some fever and general fatigue and recovered without any complications. In contrast, older age groups get severely ill with higher rates of poor recovery and deaths. Vaccination is the only hope to return to regular routines, such as school attendance and public gatherings. A total of 3,984,596,440 vaccine doses have been administered by August 5, 2021. The inability to match the increasing demand for vaccinations with their production led to prioritization policies. Vaccine prioritization policies include the highest risk groups most vulnerable to 
fatality from the virus; this includes old age and those with underlying health conditions [1].

This prioritization policy is debatable. Seroconversion from vaccination in vulnerable groups is lesser than seroconversion in non-vulnerable groups. Wei et al. studied anti-spike IgG levels in different age groups for two vaccines: ChAdOx1 and BNT162b2. In their study, the elder group had lower seroconversion than the younger-aged group. They noted a marked decline of the titers of anti-spike antibodies with aging. Titers from ChadOx1 were $127 \mathrm{ml}$ in 20 -year-old patients and declined gradually to $73 \mathrm{ml}$ in patients above the age of 80 . The BNT 162b2 antibody response followed the same pattern across age groups, with a titer of $334 \mathrm{~mL}$ in 20-year-old recipients and decreasing to 113 in recipients over 80 years of age $[2,3]$.

Table 1 discusses the COVID-19 vaccines granted emergency use by the WHO (World Health Organization) and the proper timing of measurement of antibody response to them after vaccination; there is no evidence that time interval for antibody testing differs across age groups [4-6].

We thereby hypothesize that vaccinating the younger generations, who are more liable to seroconvert, might provide better community protection than the current vaccine prioritization policy. This might raise some ethical considerations, which we will be discussing at the end of this article.

\section{Main text}

\section{Molecular mechanisms underlying decreased seroconversion rates in old age}

Several cellular and molecular changes are associated with aging. Including thymic involution, oxidative stress, proteostasis, telomere attrition, epigenetic alterations,
DNA damage signaling, epigenetic alterations, and transcriptional deviations. These changes affect the immune response to vaccination or infection, leading to immunosenescence or the gradual decrease in immune system efficiency in the elderly-especially the adaptive immune response. Some of the molecular mechanisms that occur as part of immuno-senescence include both cellular and humoral immunity [7].

\section{B cells}

As part of the aging process, the body produces fewer B cells. In mice, bone marrow inflammation and decreased production of IL-7, used for the proliferation of naive B cells, led to a reduced output of B cells [8]. Moreover, studies proved an inverse relationship between age and plasma levels of B-cell activating factor (BAF) and a proliferation-inducing ligand (APRIL), both of which can reduce $B$ cell survival in the elderly [9].

Aging does not only affect the number of B cells but also affect their function. There is a decrease in the level of modulators of the B-cell development and differentiation [10]. Namely, E2A gene products are necessary for pro-B-cell production in the bone marrow [11]. RAG enzymes and lambda- 5 are also crucial for maturation during the pro and pre-B-cell stages [12].

The long-term function of B cells is affected, too. Class switch recombination (CSR) is the process by which an IgM-producing B cell becomes an IgG-producing B cell. CSR is directly affected by activation-induced cytidine deaminase (AID), regulated by transcription factor E47. Poorer quality E47 mRNA has been found in aged B cells resulting in reduced quantities of AID, and defective CSR and somatic hypermutation [13]. There are also peroxisome proliferator-activated receptors (PPARs), nuclear hormone receptors. They prolong B-cell memory and

Table 1 Seroconversion testing granted emergency authorization by the WHO (reference in text [4-6])

\begin{tabular}{|c|c|c|c|c|}
\hline 0 & Trade name & Type & Dosage interval & $\begin{array}{l}\text { Least interval for } \\
\text { antibody testing after } \\
\text { vaccination }^{\mathrm{a}}\end{array}$ \\
\hline mRNA-1273 & Moderna & mRNA-based & 2 doses, 28 days apart & 14 days after 2 nd dose \\
\hline BNT162b2 & Pfizer/BionTech & mRNA-based & 2 doses, 21 days apart & 7 days after 2 nd dose \\
\hline Ad26.COV2.S & Janssen (Johnson\&Johnson) & Non-replicating viral vector & 1 dose or 2 doses 56 days apart & 14 days after 2 nd dose \\
\hline AZD1222 & Oxford/AstraZeneca & Non-replicating viral vector & 2 doses, 28 days apart & 14 days after 2 nd dose \\
\hline BBIBP-CorV (Vero Cells) & Sinopharm (Beijing) & Inactivated & $\begin{array}{l}2 \text { doses with 2-4 weeks interval } \\
\text { between }\end{array}$ & 14 days after 2 nd dose \\
\hline CoronaVac & Sinovac & Inactivated & $\begin{array}{l}2 \text { doses with 2-4 weeks interval } \\
\text { between }\end{array}$ & 14 days after 2 nd dose \\
\hline
\end{tabular}

Ad adenovirus, AZ Astrazeneca, BBIBP-CorV Beijing Institute of Biological Products, Sinopharm corona virus vaccine, BNT Biontech, CoV coronaviridae, COVID-19 coronavirus disease 2019, mRNA messenger ribonucleic acid, SARS severe acute respiratory syndrome, WHO World Health Organization

${ }^{a}$ Standard antibody test: total immunoglobulin levels to the receptor-binding domain of the SARS-CoV-2 spike protein were measured with an anti-SARS-CoV-2 S enzyme immunoassay 
improve the secondary antibody response. They do so by upregulating anti-apoptotic factors and shifting the metabolism of the B cells to pyruvate kinase to increase their metabolic fitness and enhance the action of the cellular supporters of the B cells (specifically dendritic and $T$ regulatory cells). They also upregulate lipoxin B4, which stimulates B cells to secrete antibodies on re-exposure [14]. PPARs are more abundant in children than adults. So, in conclusion, PPARs' positive effects on seroconversion and vaccination are reduced with aging [7].

\section{$T$ cells}

As regards to $\mathrm{T}$ cells, firstly, we will be discussing the changes observed in thymopoiesis with advancing age and the suggested molecular causes. The cytokine milieu provides normal thymus function. Due to senescence, cytokines' expression tends to differ. IL-7 levels do not vary significantly with age, which leads us to believe that changes in IL-7 levels have little effect on thymic involution in the elderly $[7,15]$. On the other hand, IL-6 levels increase and cause thymus involution and a reduced T-cell number in peripheral blood. Exogenous IL-6 leads to an acute and rapid response [16, 17]. The sensitivity of the thymus gland to cytokines raises thoughts around using interventional therapy to enhance immune responses [7].

One of the theories mentioned that cytokine milieu, especially IL- 6 production, is directly affected by the normal increase of adipogenesis (and atrophy of the thymus tissue) commonly seen with age. Thus, caloric restriction was tested to decrease adipose formation within the thymus and lead to slower involution [18].

Other cytokines such as LIF (leukemia inhibitory factor) and hormones such as corticosteroids have been linked to thymic involution as well [15]. TGF $\beta$ also plays a direct role in thymic involution [19].

Tristetraprolin is an RNA-binding protein that is also inactivated with age by P38 mitogen-activated protein kinases (p38-MAPK). Tristetraprolin regulates the transcription of proinflammatory cytokines, which explains their dysregulation with age [7].

Lastly, PPARs, which are less expressed in adults, prolong T-cell memory as well. PPARs achieve the latter by increasing the development of $\mathrm{T}$ regulatory cells, which stimulate $\mathrm{T}$ cell memory, upregulating $\gamma \delta$ type of $\mathrm{T}$ cells, which can develop long-lasting memory. Thus, shifting the metabolism of $\mathrm{T}$ cells to fatty acid oxidation, critical for the longevity of memory cells and antagonizing PDL, which hinders the development of $\mathrm{T}$ memory cells.

PPAR agonists could potentially boost the functions of both B memory and T memory cells to enhance seroconversion [14].
Shifting to myelocytes, a study on the evaluation of innate immunity demonstrated that the pathogen recognition receptor, toll-like receptor TLR1 has reduced expression levels with aging [20].

There is also evidence of cross-regulation between oxidative stress, PPARs, and nuclear factor-kB (NFkB). We know that the induction of PPARs decreases with age and that PPAR $\gamma$ downregulates the activation of macrophages [21]. The dysregulation of NFkB, produced by macrophages, may explain the disrupted inflammatory process with aging since the NFkB pathway is considered a prototypical proinflammatory signaling pathway [7].

Immuno-senescence negatively affects the seroconversion status in the elderly. As such, children might be better seroconverters. Prioritizing children in COVID-19 vaccination programs will ensure administration to those who have the most optimal response to them. Offering protection to children and, indirectly, the elderly through herd immunity.

\section{Evidence of decreased seroconversion rates in chronic conditions from non-COVID-19 vaccines}

Seroconversion is also affected by chronic diseases. One of the pathological factors that might have an impact on seroconversion is chronic kidney disease. Da Roza et al. observed the relationship between patients affected with CKD and their seroconversion status after the HBV vaccine. The primary outcome measure was a hepatitis $B$ surface antibody titer of more than 10 IU 3 months after the vaccination schedule. The study population was 165 patients, including $64 \%$ men with a mean age of 60 , mean serum creatinine level of $3.4 \pm 1.5 \mathrm{mg} / \mathrm{dL}(300 \pm$ $133 \mu \mathrm{mol} / \mathrm{L}$ ), and median estimated glomerular filtration rate (GFR) of $20 \mathrm{~mL} / \mathrm{min}$ (interquartile range, 14 to 20 ). Patients with the lowest levels of kidney function and those who were older or had diabetes were less likely to seroconvert [22].

\section{Evidence of decreased seroconversion in older age from non-COVID-19 vaccines and COVID-19 vaccines}

As discussed above, due to an immune function decline, elderly subjects do not respond as efficiently as younger individuals. Some studies show no significant decrease in the seroconversion rate; however, most of the literature supports a significant decline. Some vaccines that have shown decreased seroconversion in the elderly are as follows:

\section{Influenza}

The Centers for Disease Control and Prevention (CDC) estimates $70-90 \%$ clinical efficacy of the influenza vaccine in young adults and $17-53 \%$ in the elderly depending on the circulating virus [23]. 
A systematic review and meta-analysis concluded that the seroprotection rate $(\mathrm{SPR})$ and seroconversion rate (SCR) of older adults for $\mathrm{A} / \mathrm{H} 1 \mathrm{~N} 1$ and $\mathrm{B} /$ Victoria were lower than those of younger adults, whereas the two age groups had similar antibody responses for A/H3N2 [24].

Moreover, the $\mathrm{H} 5 \mathrm{~N} 1$ influenza vaccine effectiveness in older adults may be lower than in younger adults [25].

Frailty (a significant geriatric syndrome characterized by diminished physiologic reserve and increased susceptibility to stressors) was associated with significant impairment in the trivalent inactivated vaccine (TIV)induced strain-specific hemagglutination inhibition (HI) titers and increased rates of influenza-like illness (ILI) and laboratory-confirmed influenza infection [26].

Furthermore, pre- and probiotics have the potential to modulate antiviral defenses and vaccination responses by altering the gut microbiota. A study in 2018 investigated the effect of a novel probiotic, combined with a prebiotic, on the $\mathrm{B}$ and $\mathrm{T}$ cell responses to seasonal influenza vaccination in young and older subjects. The profiles of $B$ and $T$ cells differed significantly between young and old subjects. Vaccination increased the number of IgA and IgG memory cells and total IgG B cells in young subjects but not in older subjects and did not affect T cell subsets [27].

\section{Hepatitis $B$}

There is no extensive data available regarding hepatitis B. However, some studies have shown an association between age (greater than 50) and decreased seroconversion rates. The study was specifically conducted among health care workers [28].

\section{Rabies}

Two papers specifically compared seroconversion in different age groups after rabies vaccine administration [29, 30]. These were discussed by Leder et al. [31]. In both studies, responses to purified duck embryo vaccine and HDCV were analyzed.

In the first study, researchers compared subjects aged $11-25$ years with those over 50 years of age. All patients were on a 6-dose post-exposure schedule. Both age groups had adequate responses and developed protective antibody titers after the fourth dose, but the older subjects' antibody titer levels were $52 \%$ lower than those of the younger group.

The second study involved 60 patients. They were divided into four age groups: $1-20$ years, $21-40$ years, 41-60 years, and > 60 years. After 2 doses of the HDCV vaccine, antibody titers were significantly lower for each older group successively. The individual mean titers showed a response that was lower across all the older patients.

\section{Japanese encephalitis virus}

Two groups with mean ages of 24 and 69 years, were compared with regards to their immune response after receiving a primary vaccination against the travel virus JEV. The older group had significantly lower antibody titers post-vaccination. This titer was presumed to be due to a lower percentage of total and naive $B$ cells in the elderly group as opposed to the younger group [32].

\section{Meningitis}

General studies performed on the adult show the effectiveness of the vaccine, but it is reported that the efficacy in children under 5 years is low and in those under 18 months practically nil [33, 34].

But it is difficult to generalize because studies carried out in young children are less frequent, and some include only a small number of children [35].

The study was conducted on young participants aged between 18 months and 19 years. The vaccine used was the polysaccharide meningococcal AC. A statistically significant linear trend $(p<0.0001)$ between seroconversion rate and age at vaccination $(38.2 \%$ in children aged $18 \pm$ 24 months, $57.5 \%$ in those aged $24 \pm 35$ months, $63.6 \%$ in those aged $36 \pm 47$ months, and $77 \%$ in those aged 48 \pm 59 months) was found. Children aged over 36 months showed a higher quantitative increase in antibodies than those under this age $(p<0.0001)$. Immunogenicity has not been demonstrated in children aged under 24 months, suggesting that the production of antibodies against the polysaccharide group $\mathrm{C}$ is different to children aged over 24 months. They observed that 1 month after vaccination, the quantitative increase in the BA titer was greater above the age of 36 months. This aspect has to be considered when indicating vaccination in young children.

\section{Hepatitis A}

Hepatitis A vaccine (formalin-inactivated) is highly immunogenic, with seroconversion after a single dose in $90-99 \%$ of children 2-16 years old and adults under $77 \mathrm{~kg}$. There are lower one-dose seroconversion rates with increasing age [36]. In young persons, seroconversion is seen in $80-90 \%$ within 2 weeks of the first dose, and $95-100 \%$ of vaccinees have had seroconversion by 4 weeks [37]. The antibody response tends to be slower in older people, and significantly lower peak titers are reached after vaccination in elderly recipients [31].

\section{Varicella-zoster}

A study by Sonia Nader et al. compared the cell-mediated immune response to the Varicella zoster vaccine in both adults and children 6 weeks following vaccination 
in 2 children's groups and 2 adult groups. Following the first dose, it was evident that there was a significantly higher response in the children's groups than in the adult groups. CMI response was reevaluated at 1 year and was higher among the pediatric population showing persistence of T-cell proliferation at 1 year in $94 \%$ of adults in comparison with $97 \%$ of children [38].

As regards humoral immunity, the development of IgG antibodies to VZV antigen was higher 6 weeks after the first dose in children than in adults. The geometric mean titers in children in one of the children's groups were significantly higher than one of the adults' groups who received the same vaccine; however, in total, combined data of both children groups and both adult groups show no significant difference. IgG antibodies persisted 1 year following vaccination in all children and only $94 \%$ of adults.

\section{Pertussis}

A cohort study by Bette Liu et al. done on a group of 333 cases and 506 control with a mean age of 61 years reveals that vaccine effectiveness in this age group was $52 \%$. The protection within 5 years after vaccination was described as "modest" by the authors [39].
Table 2 displays the vaccine examples.

\section{Does COVID-19 vaccination decrease viral shedding?}

It is evident from the above that seroconversion from COVID-19 is more likely to occur in younger individuals rather than old-aged individuals. To fulfill the suggested hypothesis, that vaccination of better seroconverters can lead to a better community protection including prevention of infection of the more vulnerable groups, we need to prove that COVID-19 vaccination reduces infectivity by reducing viral load. A brief communication by LevineTiefenbrun and colleagues compared nasopharyngeal viral loads in vaccinated vs. unvaccinated individual 12 days after vaccination; they found that the mean viral load substantially decreased 12 days after vaccination with the first vaccine dose, coinciding with the known early onset of vaccine-mediated protection.

This could mean that changing policies of vaccine prioritization can serve as a better protection not only for vaccinated young adults but for the old aged as well.

Table 2 Vaccine examples showing decreased seroconversion in the elderly

\begin{tabular}{|c|c|c|}
\hline Vaccine & Authors [reference number in text] & Title \\
\hline \multirow[t]{4}{*}{ Influenza } & Goodwin et al. [20] & Antibody response to influenza vaccination in the elderly: a quantitative review \\
\hline & Meng et al. [21] & $\begin{array}{l}\text { Immunogenicity of influenza vaccine in elderly people: a systematic review and } \\
\text { meta-analysis of randomized controlled trials, and its association with real-world } \\
\text { effectiveness }\end{array}$ \\
\hline & Zhang et al. [22] & $\begin{array}{l}\text { Immunogenicity of H5N1 influenza vaccines in elderly adults: a systematic review } \\
\text { and meta-analysis }\end{array}$ \\
\hline & Yao et al. [23] & $\begin{array}{l}\text { Frailty is associated with impairment of vaccine-induced antibody response and } \\
\text { increase in post-vaccination influenza infection in community-dwelling older } \\
\text { adults }\end{array}$ \\
\hline Hepatitis B & Havlichek et al. [25] & Age-related hepatitis B seroconversion rates in health care workers \\
\hline \multirow[t]{2}{*}{ Rabies } & Ceddia et al. [26] & $\begin{array}{l}\text { Antibody response to rabies vaccine prepared in tissue cultures of human diploid } \\
\text { cells and inactivated, evaluated in different classes of age }\end{array}$ \\
\hline & Mastroeni et al. [27] & Immune response of the elderly to rabies vaccines \\
\hline Japanese encephalitis virus & Wagner et al. [29] & $\begin{array}{l}\text { Age-related differences in humoral and cellular immune responses after primary } \\
\text { immunisation: indications for stratified vaccination schedules }\end{array}$ \\
\hline \multirow[t]{3}{*}{ Meningitis } & King et al. [30] & $\begin{array}{l}\text { Total and functional antibody response to a quadrivalent meningococcal polysac- } \\
\text { charide vaccine among children }\end{array}$ \\
\hline & de Costa \& Martins Carlos Klein [31] & $\begin{array}{l}\text { Evaluation of the protective efficacy of an antimeningococcal vaccine for sero- } \\
\text { groups B and C Neisseria meningitidis infections in Brazil, 1990/92 }\end{array}$ \\
\hline & Espín Ríos et al. [32] & $\begin{array}{l}\text { Seroconversion and duration of immunity after vaccination against group } C \\
\text { meningococcal infection in young children }\end{array}$ \\
\hline Hepatitis A & Nalin et al. [33] & $\begin{array}{l}\text { Worldwide experience with the CR326F-derived inactivated hepatitis A virus vac- } \\
\text { cine in pediatric and adult populations: an overview }\end{array}$ \\
\hline Varicella-zoster & André et al. [34] & $\begin{array}{l}\text { Clinical assessment of the safety and efficacy of an inactivated hepatitis A vaccine: } \\
\text { rationale and summary of findings }\end{array}$ \\
\hline Pertussis & Nader et al. [35] & $\begin{array}{l}\text { Age-related differences in cell-mediated immunity to varicella-zoster virus among } \\
\text { children and adults immunized with live attenuated varicella vaccine }\end{array}$ \\
\hline
\end{tabular}




\section{Ethical considerations}

The idea of protecting one group through another is not new. Pregnant women, for example, consume folic acid to protect their babies, even though it could have adverse effects due to allergic reactions. Another example is the influenza vaccines, which are better in achieving immunity when targeted at children even though the elderly are getting most of the benefits [40].

The first concern is long-term safety. Kostoff et al. and $\mathrm{Wu}$ et al. could not guarantee the long-term safety of COVID-19 vaccines yet [41]. In order to be able to form an informed decision about child vaccination, pharmaceutical companies must continue their clinical studies to provide us with a better understanding of the long-term side effects of COVID-19 vaccines [42], especially not in subgroups such as children, pregnant women, and people with chronic illnesses; more research is needed [43].

Ensuring the safety of the vaccine for children and maintaining a risk-benefit balance is critical. However, even with limited information regarding safety in children, the WHO's Strategic Advisory Group of Experts (SAGE) has recently announced that the Pfizer/Biotech vaccine is safe for people aged 12 years and above [44].

Other ethical problems are that children cannot choose whether they get the vaccine or not and the ability of governments to deal with vaccine refusal. There are three main justifications for vaccine refusal in the modern world:

$>$ The philosophical (worldview) is based on a liberal understanding of anyone's right to self-determination of their health, body, and life. As a result, no one, including the government, can interfere with a person's freedom to seek or refuse medical treatment.

$>$ The religious view advocates that those compulsory vaccinations violate the freedom of religion. Not all faiths accept vaccination. The Amish, for example, believe that vaccines are unimportant because they weaken the immune system, which serves as the body's natural defense.

$>$ The medical view evaluates vaccines through side effects and possible complications. This point, especially in the context of the COVID-19 vaccines, seems justifiable, due to the lack of data on the longterm safety of the newly released vaccines.

\section{Conclusion}

Children and adolescents are at higher likelihood to display a better immune response from vaccination compared with older individuals and patients with chronic

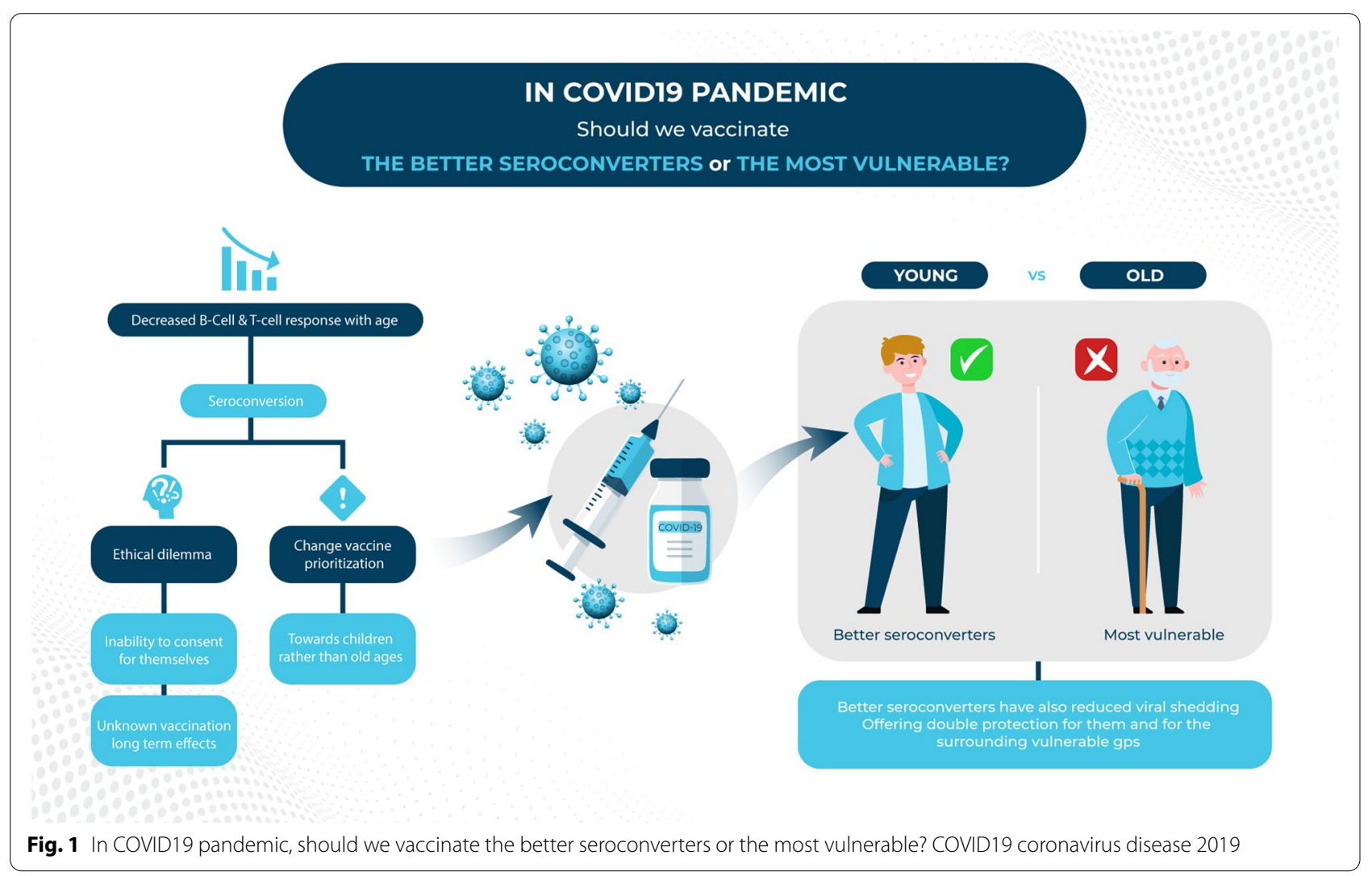


diseases. Better seroconversion also reduces viral shedding. This might mean a double protection to the vaccinated individuals and to the vulnerable groups surrounding them. Adopting this policy might be a gamechanger in COVID-19 vaccination prioritization policies, but some ethical dilemmas should first be discussed, the most important of which is the unknown long-term effects of the fast-tracked COVID-19 vaccines. Figure 1 summarizes the discussed aspects in the article.

\begin{abstract}
Abbreviations
COVID-19: Coronavirus disease 2019; CSR: Class switching recombination; HDCV: Human diploid cell vaccine; Ig: Immunoglobulins; IL: Interleukin; IPV: Inactivated polio vaccine; JEV: Japanese encephalitis virus; LIF: Leukemia inhibitory factor; MAPK: Mitogen-activated protein kinases; NF: Nuclear factor; OPV: Oral polio vaccine; PPAR: Peroxisome proliferator-activated receptor; RAG : Recombinating activating genes; TGF: Transforming growth factor; TLR: Tolllike receptor; VZV: Varicella-zoster virus.
\end{abstract}

\section{Acknowledgments}

We give acknowledgments to our families who are bearing the weight of our sacrifice of time to our patients. If our families were not understanding to the depth of our struggle, we would have never been able to keep the same level of dedication to our patients. We thank our students that we involve in each step of our researches to make them flourish in this field and take the lead the soonest the possible.

\section{Authors' contributions}

$A A, M S$, and $H G$ contributed in the conception of the idea. AA, MS, HG, MH, $N G, R J H, N S, A R A, B H, N H, M M, H I, S S, R S, H Z, G M, H M, A G, A K, M R, M K, R R, N R$, MK, $H A, R H, A K$, and RF contributed equally to drafting and revision of the manuscript. The authors (AA, MS, HG, MH, NG, RJH, NS, ARA, BH, NH, MM, HI, $\mathrm{SS}, \mathrm{RS}, \mathrm{HZ}, \mathrm{GM}, \mathrm{HM}, \mathrm{AG}, \mathrm{AK}, \mathrm{MR}, \mathrm{MK}, \mathrm{RR}, \mathrm{NR}, \mathrm{MK}, \mathrm{HA}, \mathrm{RH}, \mathrm{AK}$, and RF) read and approved the final manuscript.

\section{Funding}

This research received no specific grant from any funding agency, commercial, or not-for-profit sectors.

\section{Availability of data and materials}

Not applicable

\section{Declarations}

Ethics approval and consent to participate

Not applicable

\section{Consent for publication}

Not applicable

\section{Competing interests}

The authors declare that they have no competing interests.

\section{Author details}

${ }^{1}$ Pediatric Cardiology Unit, Pediatrics Department, Faculty of Medicine, Cairo University, Giza, Egypt. ${ }^{2}$ Pediatric Cardio-Oncology Clinic, Children Cancer Hospital of Egypt, Cairo, Egypt. ${ }^{3}$ Student and Internship Research Program (Research Accessibility Team), Faculty of Medicine, Cairo University, Giza, Egypt. ${ }^{4}$ Faculty of Dentistry, Cairo University, Giza, Egypt. ${ }^{5}$ Pixagon Graphic Design Agency, Cairo, Egypt. ${ }^{6}$ Clinical and Chemical Pathology Department, Faculty of Medicine, Cairo University, Cairo, Egypt. ${ }^{7}$ Pediatrics Department, Faculty of Medicine, Cairo University, Giza, Egypt.

Received: 21 October 2021 Accepted: 10 November 2021 Published online: 02 December 2021
References

1. Engla NEW, Journal ND (2021) N Engl J:589-591

2. Wei J et al (2021) Antibody responses to SARS-CoV-2 vaccines in 45,965 adults from the general population of the United Kingdom. Nat Microbiol 6:1140-1149

3. Ciabattini A et al (2018) Vaccination in the elderly: the challenge of immune changes with aging. Semin Immunol 40:83-94

4. Ewer $\mathrm{KJ}$ et al (2021) T cell and antibody responses induced by a single dose of ChAdOx1 nCoV-19 (AZD1222) vaccine in a phase 1/2 clinical trial. Nat Med 27:270-278

5. Ebinger JE et al (2021) Antibody responses to the BNT162b2 mRNA vaccine in individuals previously infected with SARS-CoV-2. Nat Med 27:981-984

6. Deplanque D, Launay O (2021) Efficacy of COVID-19 vaccines: from clinical trials to real life. Therapies 76

7. Ponnappan S, Ponnappan U (2011) Aging and immune function: molecular mechanisms to interventions. Antioxid Redox Signal 14:1551-1585

8. Stephan RP, Sanders VM, Witte PL (1996) Stage-specific alterations in murine B lymphopoiesis with age. Int Immunol 8:509-518

9. Jin R et al (2008) Age-related changes in BAFF and APRIL profiles and upregulation of BAFF and APRIL expression in patients with primary antibody deficieny. Int J Mol Med 21:233-238

10. Cancro MP et al (2009) B cells and aging: molecules and mechanisms. Trends Immunol 30:313-318

11. Riley RL, Blomberg BB, Frasca D (2005) B cells, E2A, and aging. Immunol Rev 205:30-47

12. Weksler ME (1995) Immune senescence: deficiency or dysregulation. Nutr Rev 53:S3-S7

13. Frasca D, Van der Put E, Riley RL, Blomberg BB (2004) Reduced Ig class switch in aged mice correlates with decreased E47 and activationinduced cytidine deaminase. J Immunol 172:2155-2162

14. AbdelMassih AF et al (2021) PPAR agonists as effective adjuvants for COVID-19 vaccines, by modifying immunogenetics: a review of literature. J Genet Eng Biotechnol 19:1-9

15. Sempowski GD et al (2000) Leukemia inhibitory factor, oncostatin M, IL-6, and stem cell factor mRNA expression in human thymus increases with age and is associated with thymic atrophy. J Immunol 164:2180-2187

16. Gruver AL, Sempowski GD (2008) Cytokines, leptin, and stress-induced thymic atrophy. J Leukoc Biol 84:915-923

17. Savino W (2006) The thymus is a common target organ in infectious diseases. PLoS Pathog 2:0472-0483

18. Yang $\mathrm{H}$, Youm $\mathrm{Y}-\mathrm{H}$, Dixit VD (2009) Inhibition of thymic adipogenesis by caloric restriction is coupled with reduction in age-related thymic involution. J Immunol 183:3040-3052

19. Kumar R, Avagyan S, Snoeck HW (2010) A quantitative trait locus on chr.4 regulates thymic involution. J Gerontol Ser A Biol Sci Med Sci 65 A:620-625

20. Panda A et al (2009) Human innate immunosenescence: causes and consequences for immunity in old age. Trends Immunol 30:325-333

21. Chung $\mathrm{HY}$ et al (2009) Molecular inflammation: underpinnings of aging and age-related diseases. Ageing Res Rev 8:18-30

22. DaRoza G et al (2003) Stage of chronic kidney disease predicts seroconversion after hepatitis B immunization: earlier is better. Am J Kidney Dis 42:1184-1192

23. K, G., C, V. \& L, S. (2006) Antibody response to influenza vaccination in the elderly: a quantitative review. Vaccine 24:1159-1169

24. Z, M. et al (2020) Immunogenicity of influenza vaccine in elderly people: a systematic review and meta-analysis of randomized controlled trials, and its association with real-world effectiveness. Hum Vacc Immunother $16: 2680-2689$

25. Zhang K, Wu X, Shi Y, Gou X, Huang J (2020) Immunogenicity of H5N1 influenza vaccines in elderly adults: a systematic review and meta-analysis. Hum Vacc Immunother 17:1-10

26. Yao X et al (2011) Frailty is associated with impairment of vaccineinduced antibody response and increase in post-vaccination influenza infection in community-dwelling older adults. Vaccine 29:5015-5021

27. Enani S et al (2018) Impact of ageing and a synbiotic on the immune response to seasonal influenza vaccination; a randomised controlled trial. Clin Nutr 37:443-451 
28. Havlichek D, Rosenman K, Simms M, Guss P (1997) Age-related hepatitis $B$ seroconversion rates in health care workers. Am J Infect Control 25:418-420

29. Antibody response to rabies vaccine prepared in tissue cultures of human diploid cells and inactivated, evaluated in different classes of age - PubMed.

30. Mastroeni I et al (1994) Immune response of the elderly to rabies vaccines. Vaccine 12:518-520

31. Leder K, Weller PF, Wilson ME (2001) Travel vaccines and elderly persons: review of vaccines available in the United States. Clin Infect Dis 33:1553-1566

32. Wagner A et al (2018) Age-related differences in humoral and cellular immune responses after primary immunisation: indications for stratified vaccination schedules. Sci Rep 8:1-2

33. King WJ et al (1996) Total and functional antibody response to a quadrivalent meningococcal polysaccharide vaccine among children. J Pediatr 128:196-202

34. de Costa EA, Martins Carlos Klein HH (1996) Avaliação da proteção conferida pela vacina antimeningocócica BC no Estado de Santa Catarina, Brazil, 1990/92 Evaluation of the protective efficacy of an antimeningococcal vaccine for serogroups $B$ and $C$ Neisseria meningitidis infections in Brazil, 1990/92. 30, 460

35. Espín Ríos I et al (2000) Seroconversion and duration of immunity after vaccination against group $\mathrm{C}$ meningococcal infection in young children. Vaccine 18:2656-2660

36. DR, N. et al (1993) Worldwide experience with the CR326F-derived inactivated hepatitis A virus vaccine in pediatric and adult populations: an overview. J Hepatol 18(Suppl 2):S51-S55

37. André FE, D'Hondt E, Delem A, Safary A (1992) Clinical assessment of the safety and efficacy of an inactivated hepatitis A vaccine: rationale and summary of findings. Vaccine 10:S160-S168

38. Nader S, Bergen R, Sharp M, Arvin AM (1995) Age-related differences in cell-mediated immunity to varicella-zoster virus among children and adults immunized with live attenuated varicella vaccine. J Infect Dis 171:13-17

39. BC L et al (2020) Effectiveness of acellular pertussis vaccine in older adults: nested matched case-control study. Clin Infect Dis 71:340-350

40. Giubilini A (2021) Vaccination ethics. Br Med Bull 137:4-12

41. Kostoff RN, Briggs MB, Porter AL, Spandidos DA, Tsatsakis A (2020) Comment: COVID-19 vaccine safety. Int J Mol Med 46:1599-1602

42. Majeed A, Papaluca M, Molokhia M (2021) Assessing the long-term safety and efficacy of COVID-19 vaccines. J R Soc Med 114:337-340

43. Wu Q et al (2021) Evaluation of the safety profile of COVID-19 vaccines: a rapid review. BMC Med 19:1-16

44. Eberhardt CS, Siegrist CA (2021) Is there a role for childhood vaccination against COVID-19? Pediatr Allergy Immunol 32:9-16

\section{Publisher's Note}

Springer Nature remains neutral with regard to jurisdictional claims in published maps and institutional affiliations.

\section{Submit your manuscript to a SpringerOpen ${ }^{\circ}$ journal and benefit from:}

- Convenient online submission

- Rigorous peer review

- Open access: articles freely available online

- High visibility within the field

- Retaining the copyright to your article

Submit your next manuscript at springeropen.com 